\title{
Gérard Ferreyrolles, Traités sur l'histoire (1638-1677). La Mothe Le Vayer, Le Moyne, Saint-Réal, Rapin
}

\section{Cecilia Russo}

\section{(2) OpenEdition}

1 Journals

\section{Edizione digitale}

URL: http://journals.openedition.org/studifrancesi/432

DOI: 10.4000/studifrancesi.432

ISSN: 2421-5856

\section{Editore}

Rosenberg \& Sellier

\section{Edizione cartacea}

Data di pubblicazione: 1 aprile 2015

Paginazione: 141-142

ISSN: 0039-2944

\section{Notizia bibliografica digitale}

Cecilia Russo, « Gérard Ferreyrolles, Traités sur I'histoire (1638-1677). La Mothe Le Vayer, Le Moyne, SaintRéal, Rapin », Studi Francesi [Online], 175 (LIX | I) | 2015, online dal 01 avril 2015, consultato il 18 septembre 2020. URL : http://journals.openedition.org/studifrancesi/432 ; DOI : https://doi.org/ 10.4000/studifrancesi.432

Questo documento è stato generato automaticamente il 18 settembre 2020.

\section{(c) $(1) \ominus$}

Studi Francesi è distribuita con Licenza Creative Commons Attribuzione - Non commerciale - Non opere derivate 4.0 Internazionale. 


\title{
Gérard Ferreyrolles, Traités sur l'histoire (1638-1677). La Mothe Le Vayer, Le Moyne, Saint-Réal, Rapin
}

\author{
Cecilia Russo
}

\section{NOTIZIA}

GÉRARD FERREYROLLES, Traités sur l'histoire (1638-1677). La Mothe Le Vayer, Le Moyne, Saint-

Réal, Rapin, avec la collaboration de Frédéric Charbonneau, Marie-Aude de Langenhagen, Béatrice Guinon, Anne Mantero, Christian Meurillon et Hélène Michon, Paris, Champion, 2013, pp. 767.

1 Si tratta di un'edizione critica realizzata nell'ambito del CELLF $17^{e}-18^{e}$ siècles, dell'Université Paris-Sorbonne, di cinque trattati francesi seicenteschi che affrontano tematiche storiche e permettono di riconsiderare la storiografia. Nell'introduzione, G. FERREYROLLES sostiene infatti la necessità di confutare l'idea che il Seicento sia stato un secolo antistorico. Nel Grand Siècle la storiografia ha senz'altro incontrato molte resistenze. Da un lato la morale religiosa dell'agostinismo, molto influente, condannando la libido sciendi e la concupiscentia oculorum, che distolgono dalla considerazione di Dio, frenava l'interesse per la storia, considerata «une vaine curiosité qui s'affuble du nom de connaissance et de science» (p. 20). Dall'altro il cartesianesimo metteva in dubbio la veridicità della storia (per Cartesio la scienza è basata sull' ingenium mentre la storia è basata sulla memoria, quindi, mentre la scienza permette all'uomo di pensare, la storia si deve accontentare di far sapere cosa pensano gli altri).

2 Tuttavia lo sviluppo dell'indagine storica fu agevolato dal progredire di alcune scienze, considerate "ausiliarie" della storia (la numismatica, la cronologia, l'archivistica e, più di tutte, la filologia) e dal nuovo interesse per la nazione e per la storia delle istituzioni correlato alla costruzione dello stato moderno (basti pensare alla Bibliothèque des 
auteurs qui ont écrit l'Histoire et Topographie de la France, prima bibliografia metodica delle fonti della storia di Francia, del 1618, a opera di André Duchesne).

3 Ferreyrolles sottolinea anche l'imprescindibile rapporto che la storia intrattiene con la scrittura, affermando che «l'histoire est écrite "en vue de raconter, non de prouver (ad narrandum, non ad probandum)"; l'historien cherche sa propre renommée par la beauté de son style, il ne cherche pas comme l'orateur la victoire par l'efficacité de sa persuasion» (p. 54). Del resto fin dalle origini l'ars historica fu considerata come letteratura e modello di eloquenza. I quattro autori di cui si presentano qui i trattati hanno visioni differenti rispetto alla storia che però, essenzialmente, è vista non come scienza ma come genere letterario. Ferreyrolles osserva che Le Moyne, riprendendo l'idea ciceroniana, definisce la storia come «une narration continue des choses vraies, grandes et publiques, écrite avec esprit, avec éloquence et avec jugement, pour l'instruction des particuliers et des princes, et pour le bien de la société civile» (p. 63). Rapin oppone la storia al romanzo: «le roman ne pense qu'à plaire, et l'Histoire ne pense qu'à instruire [...] on en distingue quatre parties dans l'histoire: la narration, le jugement, les harangues et les digressions. La narration a pour matière des faits authentiques et illustres» (p. 64). Per César Vichard de Saint-Réal «la fonction de l'Histoire consiste au contraire à fournir un trésor de faits et de paroles où le moraliste peut saisir la vérité générale du cœur humain» (p. 475). Al contrario François De La Mothe Le Vayer afferma che «il n'est pas du tout sûr qu'écrire l'histoire soit véritablement possible; c'est à défaut qu'il écrira sur elle» (p. 114).

Il volume contiene l'edizione dei testi seguenti.

5 François DE LA MOTHE LE VAYER, Discours de l'Histoire (1638); Du peu de certitude qu'il y a dans l'histoire (1668) (a cura di F. Charbonneau e H. Michon). Quest'autore fu sempre critico rispetto allo statuto della storia e alla sua utilità. Nel primo testo, appartenente all'epoca del ministero di Richelieu, egli trattiene però prudentemente l'espressione del proprio scetticismo mentre nel secondo lo manifesta apertamente.

6 Pierre LE MoYNE, De l'Histoire (1670) (a cura di M.-A. De Langenhagen e A. Mantero). L'opera, mai ripubblicata, era destinata ad accompagnare una monumentale storia sul regno di Luigi XIII che non fu mai editata e il cui manoscritto è andato perduto. Se ne apprezzano la chiarezza dell'esposizione, l'abbondanza delle informazioni e degli aneddoti. L'apparente semplicità racchiude uno spessore informativo e concettuale che, al di là del sapere dell'autore, trasmette una grande varietà di tradizioni storiografiche.

7 César VICHARD DE SAINT-RÉAL, De l'usage de l'histoire (1671) (a cura di C. Meurillon). Ha conosciuto una fortuna editoriale molto contrastata nel tempo: pubblicato nel 1671, rieditato due volte nel 1672, ebbe molte riedizioni tra il 1713 e il 1772 e ben dodici tra il 1803 e il 1830 .

8 Il progetto di Saint-Réal si distingue da quello dei suoi predecessori per il fatto che non si concentra né sul metodo né sulla scrittura della storia, ma sulla lettura. Non pone l'accento sulla produzione ma sull'uso che se ne può fare: «L'intérêt de l'Histoire est double. Par les histoires qu'elle rapporte, elle fait voir la folie ou la faiblesse de l'esprit humain, qui est la chose du monde la plus nécessaire à savoir. [...] Savoir, c'est connaître les choses par leur causes; ainsi savoir l'Histoire c'est connaître les hommes qui en fournissent la matière, c'est juger de ces hommes sainement; étudier l'Histoire c'est étudier les motifs, les opinions et les passions des hommes, pour en connaitre tous 
les ressorts, les tours et les détours, enfin toutes les illusions qu'elles savent faire aux esprits, et les surprises qu'elles font aux cœurs» (p. 474).

9 René RAPIN, Instructions pour l'histoire (a cura di B. Guinon). Pubblicato per la prima volta nel 1677, senza il nome dell'autore, poi rieditato dall'autore nel 1684 all'interno della raccolta Comparaisons et Réflexions col titolo Réflexions sur l'histoire. Rapin afferma l'importanza della storia osservando che «on ne peut rien savoir en perfection dans les belles lettres, que par le commerce des Anciens» (p. 567). La sua ottica retorica non lascia spazio a interrogativi di ordine epistemologico sulla natura né sulla possibilità della conoscenza storica. La storia è vista come narrazione e, nel trattato, cinque capitoli sono dedicati allo stile e solo l'ultimo alla materia. 